\title{
Oral hygiene status of the orphan children in Ar-Rohman Foster Home Bandung after dental health education
}

\author{
Nurayni Tri Hapsari*, Anne Agustina Suwargiani*, Cucu Zubaedah* \\ *Department of Community Dentistry Faculty of Dentistry Universitas Padjadjaran, Indonesia
}

\begin{abstract}
Introduction: Oral hygiene status is a condition of a person's oral cavity. Oral hygiene status can be assessed using Oral Hygiene Index Simplified (OHI-S) by Greene \& Vermillion. The education given regarding dental health is one of the health promotion with the purpose to increase the ability of children in terms of maintaining and improving their oral hygiene. The purpose of this study was to determine the oral hygiene status of the orphan children in Ar-Rohman Foster Home Bandung before and after being given dental health education (DHE). Methods: This research was pre-experimental research with one group of pretest-posttest design with total sampling technique. Subjects of this research were orphans aged 1315 years old. The respondents got the clinical examination of OHI-S at before and after the respondent was given dental health education. The data obtained then tested using the normality test, if the data were normally distributed analysis, then analyzed with a paired t-test, and if the data were not normally distributed, will be analyzed with a Wilcoxon test. Results: The results showed a significant decrease of plaque index after dental health education was given to the orphans. The examination of the calculus index (Cl-S) did not show any change before and after dental health education. OHI-S of children, however, showed a significant decrease. Conclusion: There was an increase in the oral hygiene status of the orphan children in Ar-Rohman Foster Home Bandung after being given dental health education.
\end{abstract}

Keywords: Oral hygiene, dental health education (DHE), orphans.

P-ISSN 1979-0201, e-ISSN 2549-6212 Available from: http://jurnal.unpad.ac.id/pjd/article/view/14321

DOI: 10.24198/pjd.vol29no3.14321

Submission: Aug 2017 Publishing: Nov 2017

\section{INTRODUCTION}

Oral health is one of the most vital components of human bodies. The poor degree of oral health will be able to disturb the quality of a human's life. ${ }^{1,2}$ Based on Indonesia Household Health
Survey in 2001, the oral disease was reported to be the sixth most common disease that the society experienced. According to the Basic Health Research in 2013, the rate of the oral disease was increasing from $23.2 \%$ to $25.9 \% .^{3}$ According to WHO in 2003, dental treatment is the

Corresponding author: Nurayni Tri H, Department of Community Dentistry Faculty of Dentistry Univ. Padjadjaran, Indonesia Jl. Sekeloa Selatan No. 1 Bandung, West Java-Indonesia, Email: nuraynitrihapsaripratiwi@gmail.com 
fourth most expensive health therapy. ${ }^{4}$ Evidently, dental problems are avertible, and their initial occurrences are reversible. Thus, it is preferable to maintain good oral health to avoid having an expensive dental treatment.

Based on previous research, the pattern of foster home living was different from the normal family living as it provided physical security, food, and shelter but was devoid of psychological security. Often these foster homes can only barely meet the needs of their inmates because of poor funding and the low caretaker compared to the child ratio. These children population at risk concerning abnormal psychosocial development. ${ }^{5}$ Research showed that the oral health status of the foster home children hasn't been able to be classified as good. ${ }^{2}$ The knowledge of the children and the caretaker at this foster home on how to maintain oral health is still lacking. Furthermore, dental health education is still rather neglected. Orphans acquire dental health education needs to be delivered to the children and the caretakers to achieve a better dental and oral health status. ${ }^{6}$ The purpose of this study was to determine the oral hygiene status of the orphan children in ArRohman Foster Home Bandung before and after being given dental health education (DHE).

\section{METHODS}

This pre-experimental study used the one group pretest-posttest design with the total sample of 31 respondents at the age of 13-15 years old. Clinical examination was conducted using Greene \& Vermilion's Oral Hygiene Index-Simplified
(OHI-S). The index was examined at the beginning of the study before given dental health education and demonstration of the proper methods of using a toothbrush and dental floss. The education was done in several times, at the $7^{\text {th }}, 14^{\text {th }}$, and $21^{\text {st }}$ day by presenting the same topics. At the $28^{\text {th }}$ day, another OHI-S examination prevailed as a final inspection. The data obtained then tested using the normality test, if the data were normally distributed analysis, then analyzed with a paired t-test, and if the data were not normally distributed, will be analyzed with a Wilcoxon test.

\section{RESULTS}

Based on Table 1 showed that before dental health education, most of the orphans has a fair category of plaque index, which was as much as 26 children (83.9\%). Most of the orphans calculus index was at the fair category, which was as much as 16 children (51.6\%), and most of the orphans $\mathrm{OHI}-\mathrm{S}$ was in the fair category, which was as much as 22 children (71\%). At the last clinical examination showed that the most of the orphans calculus index was changed to the good category, which was as much as 25 children (80.6\%). After dental health education was given, most of the orphans $\mathrm{OHI}-\mathrm{S}$ score was in a good category, which was as much as 23 children (74.2\%). The final result in the $28^{\text {th }}$ day, after three times given dental health education and demonstration, showed a significant decrease in the OHI-S score from 1.7742 to 1.0742 , and also a decrease on the plaque index score from 1.1129 to 0.4129 . However, the calculus index was found to be persistent in the score of 0.6606 .

Table 1. Distribution of the plaque, calculus, and OHI-S index of orphans in Ar-Rohman Foster Home Bandung

\begin{tabular}{|c|c|c|c|c|c|c|c|c|c|}
\hline \multirow{3}{*}{ Indicator } & \multirow{3}{*}{ Category } & \multirow{3}{*}{$\begin{array}{c}\text { Before DHE } \\
n\end{array}$} & \multicolumn{7}{|c|}{ After DHE } \\
\hline & & & \multicolumn{2}{|c|}{$1^{\text {st }}$} & \multicolumn{2}{|c|}{$2^{\text {nd }}$} & \multicolumn{2}{|c|}{$3^{\text {rd }}$} & \multirow[b]{2}{*}{$\%$} \\
\hline & & & $\%$ & $\mathrm{n}$ & $\%$ & $n$ & $\%$ & $n$ & \\
\hline \multirow[t]{3}{*}{ Plaque } & Good & 4 & 12.9 & 8 & 25.8 & 17 & 54.8 & 25 & 80.6 \\
\hline & Fair & 26 & 83.9 & 23 & 74.2 & 14 & 45.2 & 6 & 19.4 \\
\hline & Poor & 1 & 3.2 & 0 & 0 & 0 & 0 & 0 & 0 \\
\hline \multirow[t]{3}{*}{ Calculus } & Good & 14 & 45.2 & 14 & 45.2 & 14 & 45.2 & 14 & 45.2 \\
\hline & Fair & 16 & 51.6 & 16 & 51.6 & 16 & 51.6 & 16 & 51.6 \\
\hline & Poor & 1 & 3.2 & 1 & 3.2 & 1 & 3.2 & 1 & 3.2 \\
\hline \multirow[t]{3}{*}{ OHI-S } & Good & 7 & 22.6 & 14 & 45.2 & 16 & 51.6 & 23 & 74.2 \\
\hline & Fair & 22 & 71 & 16 & 51.6 & 14 & 45.2 & 8 & 25.8 \\
\hline & Poor & 2 & 6.4 & 1 & 3.2 & 1 & 3.2 & 0 & 0 \\
\hline
\end{tabular}


Tabel 2. The plaque, calculus, and $\mathrm{OHI}-\mathrm{S}$ index of the orphans in Ar-Rohman Foster Home Bandung

\begin{tabular}{|c|c|c|c|c|c|}
\hline \multirow{2}{*}{ Indicator } & \multirow{2}{*}{ Value } & \multirow{2}{*}{$\begin{array}{l}\text { Before } \\
\text { DHE }\end{array}$} & \multicolumn{3}{|c|}{ After DHE } \\
\hline & & & $1^{\text {st }}$ & $2^{\text {nd }}$ & $3^{\text {rd }}$ \\
\hline \multirow{4}{*}{$\begin{array}{l}\text { Plaque } \\
\text { Index }\end{array}$} & Average & 1.1129 & 0.8223 & 0.6616 & 0.4129 \\
\hline & $\operatorname{Max}$ & 2.00 & 1.50 & 1.83 & 1.17 \\
\hline & Min & 0.33 & 0.33 & 0.17 & 0.00 \\
\hline & Sd & 0.41341 & 0.32760 & 0.34273 & 0.26145 \\
\hline \multirow{4}{*}{$\begin{array}{l}\text { Calculus } \\
\text { Index }\end{array}$} & Average & 0.6606 & 0.6606 & 0.6606 & 0.6606 \\
\hline & $\operatorname{Max}$ & 2.00 & 2.00 & 2.00 & 2.00 \\
\hline & Min & 0.00 & 0.00 & 0.00 & 0.00 \\
\hline & Sd & 0.50292 & 0.50292 & 0.50292 & 0.50292 \\
\hline \multirow{4}{*}{$\begin{array}{l}\text { OHI-S } \\
\text { Index }\end{array}$} & Average & 1.7742 & 1.4829 & 1.3226 & 1.0742 \\
\hline & $\operatorname{Max}$ & 3.83 & 3.33 & 3.17 & 2.67 \\
\hline & Min & 0.50 & 0.67 & 0.17 & 0.17 \\
\hline & Sd & 0.81576 & 0.66709 & 0.4052 & 0.54084 \\
\hline
\end{tabular}

Table 3. The normality test of the plaque, calculus, and $\mathrm{OHI}-\mathrm{S}$ Index of the orphans in Ar-Rohman Foster Home Bandung

\begin{tabular}{|c|c|c|c|c|}
\hline \multirow{2}{*}{ Indicator } & \multirow{2}{*}{ Category } & \multicolumn{3}{|c|}{ Value } \\
\hline & & Statistic & Df & Sig. \\
\hline \multirow{4}{*}{$\begin{array}{l}\text { Plaque } \\
\text { Index }\end{array}$} & Before DHE & 0.971 & 31 & 0.537 \\
\hline & After $1^{\text {st }} \mathrm{DHE}$ & 0.946 & 31 & 0.118 \\
\hline & After $2^{\text {nd }} \mathrm{DHE}$ & 0.866 & 31 & 0.001 \\
\hline & After $3^{\text {rd }} \mathrm{DHE}$ & 0.902 & 31 & 0.008 \\
\hline \multirow{4}{*}{$\begin{array}{l}\text { Calculus } \\
\text { Index }\end{array}$} & Before DHE & 0.924 & 31 & 0.030 \\
\hline & After $1^{\text {st }} \mathrm{DHE}$ & 0.924 & 31 & 0.030 \\
\hline & After $2^{\text {nd }} \mathrm{DHE}$ & 0.924 & 31 & 0.030 \\
\hline & After $3^{\text {rd }} \mathrm{DHE}$ & 0.924 & 31 & 0.030 \\
\hline \multirow{4}{*}{$\begin{array}{l}\text { OHI-S } \\
\text { Index }\end{array}$} & Before DHE & 0.937 & 31 & 0.069 \\
\hline & After $1^{\text {st }} \mathrm{DHE}$ & 0.913 & 31 & 0.015 \\
\hline & After $2^{\text {nd }} D H E$ & 0.924 & 31 & 0.029 \\
\hline & After $3^{\text {rd }} \mathrm{DHE}$ & 0.944 & 31 & 0.109 \\
\hline
\end{tabular}

Table 4. The test results before and after Dental Health Education (DHE)

\begin{tabular}{clc}
\hline & \multicolumn{1}{c}{ Indicator } & $\begin{array}{c}\text { Before and After Dental } \\
\text { Health Education (DHE) }\end{array}$ \\
\hline Plaque & $\mathrm{Z}$ & $-4.710^{\mathrm{b}}$ \\
Index & Asymp. Sig. (2-tailed) & 0.000 \\
\hline Calculus & $\mathrm{Z}$ & $-4.709^{\mathrm{b}}$ \\
Index & Asymp. Sig. (2-tailed) & 1.000 \\
\hline \multirow{2}{*}{ Calculus } & $\mathrm{T}$ & 8.545 \\
Index & df & 30 \\
& Sig. (2-tailed) & 0.000 \\
\hline
\end{tabular}

\section{DISCUSSION}

The decrease in plaque index values occurred after being given dental health education for three times. Research conducted by Kumar et al. in 2016 mentioned a significant decrease of the plaque index occurred in the children aged 12-18 years old after being given dental health education by means of the Power Point $\circledast$ presentation. ${ }^{7}$ The study found a decrease in the plaque index value from 1.95 to 0.65 within four weeks. Another study conducted by Maheswari et al. among the children aged 8-10 years old in comparing the effectiveness of oral hygiene education through conventional techniques and the combination of conventional techniques with games, resulted in a significant decrease of the plaque index in both techniques. $^{8}$

There was a change of the plaque index of the orphans in Ar-Rohman foster home Bandung after being given dental health education for three times. The change of the plaque index has occurred from the seventh day after the first counseling, and the plaque index was increasing significantly after being given the third counseling. Repeated counseling will give a better effect. The repetition aims to strengthen the message of dental health education. ${ }^{9}$

Changes in the plaque index of the children were occurring due to the habit changes, such as changes in maintaining oral hygiene after being given dental health education. Dental health education given in this research was regarding the oral and dental health care, including mechanical plaque control. Mechanical and chemical plaque control may decrease the plaque index. ${ }^{10}$ Oral hygiene instruction being given was the action of preventing plaque and calculus from accumulating and to removing the plaque in the oral cavity. ${ }^{11}$

Besides the plaque index, the calculus index examination was also performed. Calculus is a hard deposit formed from plaque mineralization. Calculus can be found on the tooth surface or dental prosthesis and usually covered by a layer of non-mineralized plaque. Examination of the calculus index conducted in this study did not show any change in calculus index value before and after the dental health education, which was in 
the value of 0.6606 . Another study has been conducted on the effectiveness of the dental health education towards the calculus and plaque index of 200 children aged 12-15 years old. The calculus index change occurred was very low, ranging from the average value of 0.40 to 0.38 with the significant value of 0.481 , inversely related to the changes in plaque index values and $\mathrm{OHI}-\mathrm{S}$ scores with significant changes. ${ }^{12}$

Also, studies conducted regarding the effectiveness of dental health education along with the use of mouthwashes twice daily, also showed no change in calculus index, either before or after the counseling and the use of mouthwash. The study was conducted among 54 naval personnel who were sailing for 201 days. In the absence of any changes in this study can be concluded that the combination of counseling and the use of mouthwash would be able to prevent the calculus formation. ${ }^{13}$

The results from the study above were different from the research conducted by Olubunmi and Olushola regarding the differences of the value of calculus index before and after dental health education using video and verbal demonstrations among 120 children ages $11-12$ years old. ${ }^{14}$ In this study, the children were given information about oral and dental health, then each respondent was given prophylactic action on the whole oral cavity and was given the same type of toothbrush and toothpaste. The OHI-S value of the respondents were 0 , and six weeks after the counseling and prophylactic action, the examination of the plaque and calculus index was repeated to measure the $\mathrm{OHI}-\mathrm{S}$ value.

The results showed that there was a significant decrease in the calculus index from both groups of video and verbal counseling technique. ${ }^{14}$ Differences in the results of some of these studies may cause by the differences in samples and treatments given to the sample.

In this study, the calculus index before and after dental health education did not show any significant changes despite being given counseling for three times. The changes only occurred in the plaque index value. During the 22 -days of the research period, the respondents had performed their oral hygiene instructions, but there was no mechanical action for the calculus removal, while dental calculus could only eliminated by using certain mechanical tools such as scalers, curettes, ultrasonic instruments or combination of such devices.

Actions that can be done using these mechanical tools are scaling and root planing. Scaling is a process of removing biofilm and supragingival and subgingival calculus on the tooth surface, whereas the root planning is an action of removing residual calculus attached to the roots and some cementum, to produce the smooth, hard, and clean tooth surface. Both actions were a unified one-piece procedure. Also, the patients still needed to be given the instructions on performing the proper oral health care. ${ }^{11}$

After the examination of plaque index and calculus index on orphans in Ar-Rohman foster home Bandung, then the calculation of the OHI-S performed by summing the plaque and calculus index value. There was a significant change in the $\mathrm{OHI}-\mathrm{S}$ value of the orphans at Ar-Rohman foster home Bandung before and after being given three times of dental health education. This result was consistent with the previous research conducted by Markeviciute and Narbutaite in 2015. Before given dental health education, the $\mathrm{OHI}-\mathrm{S}$ value of the orphans was in the fair and poor category, but after the counseling, the OHI-S value was changed into the good and fair category. ${ }^{2}$ Also, another study regarding the effectiveness of dental and oral health education for 12-15-year-old children in India, with the total sample of 205 respondents showed a significant decrease in $\mathrm{OHI}-\mathrm{S}$ values af ter given the counseling twice. ${ }^{12}$

The OHI-S value depends on the plaque and calculus presence in the oral cavity because the $\mathrm{OHI}-\mathrm{S}$ value is calculated from the sum of the plaque and calculus index value. Although in this study the calculus index value of the orphans did not show any significant change, the plaque index value was changed significantly, so the $\mathrm{OHI}-\mathrm{S}$ value of the orphans in Ar-Rohman foster home was also changed significantly. The $\mathrm{OHI}-\mathrm{S}$ value describes the oral hygiene. If a person keeps their oral and hygiene properly, then the OHI-S value will be in a good category. The effective and efficient dental and oral care will establish a good oral health. ${ }^{16}$

Education is one effective way of improving the oral health. Education provides information on the proper dental and oral health care. In this study, the counseling materials given to the 
orphans in Ar-Rohman foster home Bandung were about the importance of maintaining oral hygiene, the impact of poor oral hygiene maintenance, proper individual oral hygiene methods, as well as a routine visit to the dentist.

Counseling given were as much as three times, which were, on the first, eighth, and the twenty-second day. The research conducted by Shenoy and Sequeira in 2010 proofed that repeated dental health education towards the children aged 12-13 years old was able to improve the children's knowledge about dental health and their skills in cleaning dental plaque. ${ }^{17}$

Optimal dental hygiene also requires motivation from the patients as well as the necessary tools and correct oral hygiene methods. ${ }^{18}$ Respondents in this study were given tools to maintain oral hygiene such as toothbrush, toothpaste, and appropriate dental floss. Instructions provided were how to brushing teeth with the proper technique and methods and also the proper use of dental floss. Tooth brushing is the easiest and most effective individual oral hygiene methods. ${ }^{18}$

\section{CONCLUSION}

There was an increase in the oral hygiene status of the orphan children in Ar-Rohman Foster Home Bandung after being given dental health education.

\section{REFERENCES}

1. Kwan SYL, Petersen PE, Pine CM, Borutta A. Health-promoting schools: an opportunity for oral health promotion. Bull WHO. Sep 2005;83:677-85.

2. Markeviciute G, Narbutaite J. Effectiveness of a motivation and practical skills development methods on the oral hygiene of orphans children in Kaunas, Lithuania. J Oral Maxillofac Res. Jun 30, 2015;6(3):e2. DOI: 10.5037/ jomr.2015.6302.

3. National Institute of Health Research and Development (NIHRD). Indonesia Basic Health Research (RISKESDAS) 2013. Jakarta: Ministry of Health Republic of Indonesia; 2013.

4. WHO. Continuous improvement of oral health in the 21st century - the approach of the WHO Global Oral Health Programme. The
World Oral Health Report 2003. Geneva: Oral Health Programme Noncommunicable Disease Prevention and Health Promotion; 2003.

5. Sharma A, Gaur A, Pareek S, Raja V, Sanadhya S, Sharma AB. Oral Health Status and Treatment Needs among Orphanage Children of Jaipur City. Sch J App Med Sci. 2014;2(5D):1776-80.

6. Ojahanon $\mathrm{PI}$, Akionbare $\mathrm{O}$, Umoh AO. The oral hygiene status of institution dwelling orphans in Benin City. Niger J Clin Prac. JanMar 2013;16(1):41-4. DOI: 10.4103/11193077.106732.

7. Kumar SGR, Narayanan MBA, Jayanthi D. Comparison of oral hygiene status before and after health education among 12-18-yearold patients. J Indian Assoc Public Health Dent. 2016;14(2):121-5. DOI: 10.4103/23195932.183813.

8. Maheswari UN, Asokan S, Asokan S, Kumaran ST. Effects of conventional vs game-based oral health education on children's oral health-related knowledge and oral hygiene status-a prospective study. Oral Health Prev Dent. 2014;12(4):331-6. DOI: 10.3290/j.ohpd. a32677.

9. Haleem A, Khan MK, Sufia S, Chaudhry S, Siddiqui MI, Khan AA. The role of repetition and reinforcement in school-based oral health education-a cluster randomized controlled trial. BMC Public Health. Jan 4, 2016;16(2):111. DOI: $10.1186 / \mathrm{s} 12889-015-2676-3$.

10. Reddy S. Essentials of Clinical Periodontology and Periodontics. $4^{\text {th }}$ ed. New Delhi: Jaypee Brothers Medical Publishers Pvt. Ltd.; 2011.

11. Newman MG, Takei H, Klokkevold PR, Carranza FA. Carranza's Clinical Periodontology. $12^{\text {th }}$ ed. Philadelphia: W.B Saunders; 2015.

12. Sanadhya YK, Thakkar JP, Divakar DD, Pareek $\mathrm{S}$, Rathore K, Yousuf A, et al. Effectiveness of oral health education on knowledge, attitude, practices and oral hygiene status among 12-15-year-old schoolchildren of fishermen of Kutch district, Gujarat, India. Int Marit Health. 2014;65(3):99-105. DOI: 10.5603/ IMH.2014.0022.

13. Wang G, Li W, Liu Y, Chen X, Huang J, Zhao $Y$, et al. Efficacy of dental health education and a novel mouthwash on periodontal health of navy personnel on a long ocean-going training mission. Int $\mathrm{J}$ Clin Exp Med. Aug 
2016;9(8):16653-60.

14. Olubunmi B, Olushola I. Effects of information diseemination usimg video of indigenous language on 11-12 years children's dental health. Ethiop J Health Sci. Nov 2013;23(3):201-8.

15. Olusile AO, Adeniyi AA, Orebanjo O. Selfrated oral health status, oral health service utilization, and oral hygiene practices among adult Nigerians. BMC Oral Health. Nov 2014;14(140):1-9. DOI: 10.1186/1472-6831-
14-140.

16. Shenoy RP, Sequeira PS. Effectiveness of a school dental education program in improving oral health knowledge and oral hygiene practices and status of 12-to 13-year-old schoold children. Indian J Dent Res. AprJun 2010;21(2):253-9. DOI: 10.4103/09709290.66652 .

17. Lindhe J, Lang NP, Karring T. Clinical Periodontology and Implant Dentistry. $6^{\text {th }}$ ed. Hoboken: Wiley Blackwell; 2015. 